\title{
Persistent luminescence in rare-earth codoped $\mathrm{Ca}_{2} \mathrm{Si}_{5} \mathrm{~N}_{8}: \mathrm{Eu}^{2+}$
}

\author{
Koen Van den Eeckhout, Philippe F. Smet and Dirk Poelman \\ LumiLab, Department of Solid State Sciences, Ghent University, Krijgslaan 281-S1, 9000 Gent, Belgium
} Paper published in J. Lumin. 2009, 129, p.1140-1143

\begin{abstract}
The luminescence properties of $\mathrm{Ca}_{2} \mathrm{Si}_{5} \mathrm{~N}_{8}: \mathrm{Eu}, \mathrm{M}$ (with $\mathrm{M}=\mathrm{Nd}, \mathrm{Sm}$, Dy, Ho or Tm) are reported. $\mathrm{Ca}_{2} \mathrm{Si}_{5} \mathrm{~N}_{8}$ :Eu without codopants shows a relatively weak afterglow. $\mathrm{Ca}_{2} \mathrm{Si}_{5} \mathrm{~N}_{8}$ :Eu,Tm shows the highest persistent emission intensity, with an orange emission colour due to a broad emission band peaking at $620 \mathrm{~nm}$. The persistence emission spectrum is red-shifted by about $10 \mathrm{~nm}$ compared to the steady state photoluminescence. Based on thermoluminescence measurements, it is shown that the addition of $\mathrm{Nd}$, Dy and $\mathrm{Ho}$ to $\mathrm{Ca}_{2} \mathrm{Si}_{5} \mathrm{~N}_{8}$ : $\mathrm{Eu}$ introduces trap states which are too shallow for considerable enhancement of the persistent luminescence. The persistent luminescence in $\mathrm{Ca}_{2} \mathrm{Si}_{5} \mathrm{~N}_{8}: \mathrm{Eu}$,Tm is efficiently excited in the visible part of the spectrum.
\end{abstract}

PACS: 78.55-m (Photoluminescence); 78.60.Kn (thermoluminescence)

Keywords: nitrides, persistent luminescence, europium, thermoluminescence, rare earth Corresponding author:

Philippe F. Smet

(T) +3292644353

(F) +3292644996

(E) philippe.smet@ugent.be 


\section{Introduction}

Nowadays more and more attention is being paid to reducing energy consumption and $\mathrm{CO}_{2}$ emission when developing new products. In this paper persistent phosphor materials, needing no other energy than ambient light, are reported. They could provide the perfect alternative to traditional emergency illumination in case of electric power failures [1]. $\mathrm{SrAl}_{2} \mathrm{O}_{4}: \mathrm{Eu}, \mathrm{Dy}$ (green, [2]), $\mathrm{CaAl}_{2} \mathrm{O}_{4}: \mathrm{Eu}, \mathrm{Nd}$ (violet, [3]) and $\mathrm{Sr}_{2} \mathrm{MgSi}_{2} \mathrm{O}_{7}: \mathrm{Eu}$,Dy (blue, [4]) all show a long afterglow with high initial brightness. However efficient materials emitting in the orange-to-red region of the visible spectrum, which would allow to make visually more prominent products, are relatively scarce [5]. $\mathrm{Y}_{2} \mathrm{O}_{2} \mathrm{~S}$ : Eu, Ti, Mg has a relatively long, intense and reddish afterglow [6,7], although the decay is considerably faster than $\mathrm{SrAl}_{2} \mathrm{O}_{4}: \mathrm{Eu}, \mathrm{Dy}$. This material has the major disadvantage of ultraviolet light being required to efficiently charge the phosphor, which limits its field of applications.

The lack of orange-to-red persistent phosphors which can still be perceived many hours after the excitation mainly relates to the following two problems:

- Most of the currently used persistent materials are based on oxides, with $\mathrm{Eu}^{2+}$ as an emitting ion. However, in oxides it is very difficult to have a sufficiently large crystal field to obtain orange or red $\mathrm{Eu}^{2+}$ emission [8].

- The eye sensitivity is much lower in the long wavelength range when the eye enters the mesopic and scotopic vision region (already for intensities below $500 \mathrm{mcd} / \mathrm{m}^{2}$ ), typical for persistent phosphor applications [1].

The first problem can be tackled by turning to other host materials for the $\mathrm{Eu}^{2+}$, such as the thiosilicates or the nitrides. We recently showed that persistence luminescence (with an emission peaking at 650 $\mathrm{nm})$ can be obtained in $\mathrm{Ca}_{2} \mathrm{SiS}_{4}: \mathrm{Eu}, \mathrm{Nd}$ [5]. Unfortunately, ultraviolet light $(\lambda \leq 360 \mathrm{~nm})$ is required for the excitation and the emission is actually too far into the red to make it visible to the human eye for a sufficiently long time.

Hence we turned to other, recently reported host materials for orange-to-red $\mathrm{Eu}^{2+}$ emission, namely the nitrides. This large class of materials is actively studied for use as colour conversion material in white light emitting diodes (LEDs) [9]. Its main advantages are a high thermal and chemical stability, and a 
high quantum efficiency for several hosts. For instance, $\mathrm{M}_{2} \mathrm{Si}_{5} \mathrm{~N}_{8}: \mathrm{Eu}^{2+}$ with $\mathrm{M}=\mathrm{Ca}$, Sr or Ba, have a broad emission peaking at $605 \mathrm{~nm}, 610 \mathrm{~nm}$ and $570 \mathrm{~nm}$ respectively (for low europium concentrations) [10]. In this work we report on the persistent luminescence of $\mathrm{Ca}_{2} \mathrm{Si}_{5} \mathrm{~N}_{8}: \mathrm{Eu}$ and the influence of codoping with the rare-earth ions neodymium, samarium, dysprosium, holmium and thulium.

\section{Experimental}

$\mathrm{Ca}_{2} \mathrm{Si}_{5} \mathrm{~N}_{8}: \mathrm{Eu}, \mathrm{RE}$ powders were prepared from appropriate mixtures of $\mathrm{Ca}_{3} \mathrm{~N}_{2}$ (99\%, Alfa Aesar), $\mathrm{Si}_{3} \mathrm{~N}_{4}$ (99.85\%, Alfa Aesar), $\mathrm{EuF}_{3}$ (99.5\%, Alfa Aesar) and $\mathrm{RE}_{2} \mathrm{O}_{3}(\mathrm{RE}=\mathrm{Nd}, \mathrm{Sm}, \mathrm{Dy}, \mathrm{Ho}$ or Tm, typically $99.9 \%$ ). Unless otherwise mentioned, the powders were prepared with $1 \mathrm{~mol} \%$ of $\mathrm{Eu}^{2+}$ (i.e. $1 \%$ substitution of the Ca ions) and $0.5 \mathrm{~mol} \%$ of $\mathrm{RE}^{3+}$ ions. All materials were weighed, ground and mixed under a protective Ar atmosphere. Then the powders were heated for $1 \mathrm{~h}$ under a reducing atmosphere $(90 \%$ nitrogen, $10 \%$ hydrogen) at $1300{ }^{\circ} \mathrm{C}$. After natural cooling of the furnace, the powders were recuperated and slightly ground.

The photoluminescence and the persistence decay of the powders were studied with a fluorescence spectrometer (FS920, Edinburgh Instruments). Thermoluminescence measurements were recorded using a contact gas cryostat (Optistat CF, Oxford Instruments) and the same spectrometer. Scanning electron microscopy (SEM) was performed using a FEI Quanta 200, equiped with EDX (energy dispersive x-ray analysis, EDAX Genesys 4000). The cathodoluminescence was monitored using the low energy channels of the EDX detector [12].

\section{Results.}

Figure 1 shows the steady state photoluminescence emission and excitation spectra for $\mathrm{Ca}_{2} \mathrm{Si}_{5} \mathrm{~N}_{8}$ :Eu. The emission spectrum, peaking at $609 \mathrm{~nm}$ is relatively broad (FWHM of $110 \mathrm{~nm}$ ). The excitation spectrum spans a broad wavelength range, limited on the short wavelength side by the host absorption [13], which appears not to be very efficient. The emission and excitation behaviour is in good correspondence with literature data [10]. Li et al. reported an emission maximum at $605 \mathrm{~nm}$ for $\mathrm{Ca}_{2} \mathrm{Si}_{5} \mathrm{~N}_{8}: \mathrm{Eu}$ with low europium concentration. Increasing the europium concentration shifts the steady state emission spectrum to $615 \mathrm{~nm}$ for a maximum Eu solubility of $7 \%$ [10]. The emission spectrum for the persistent luminescence in $\mathrm{Ca}_{2} \mathrm{Si}_{5} \mathrm{~N}_{8}: \mathrm{Eu}, \mathrm{Tm}$ (Fig. 1) peaks at $620 \mathrm{~nm}$, which is red-shifted by about $10 \mathrm{~nm}$ compared to the steady state emission. We observed no changes in the emission spectrum during the decay 
of the persistent luminescence. Furthermore, the excitation spectrum for the persistent luminescence (i.e. the wavelengths which are suitable to induce the persistent luminescence) appears to be similar to the steady state excitation spectrum, although it is difficult to measure this accurately [5]. It was verified that both ultraviolet and blue-to-green visible light are suitable to charge the phosphors, which makes the persistent luminescence efficient for applications where charging is performed by artificial light sources or ambient daylight.

In Figure 2 the decay profiles for the persistent emission are shown for several $\mathrm{Ca}_{2} \mathrm{Si}_{5} \mathrm{~N}_{8}: \mathrm{Eu}, \mathrm{RE}$ powders after excitation at $400 \mathrm{~nm}$.

The intensity of the persistent luminescence is plotted in Fig. 3 for all the powders studied, measured $20 \mathrm{~s}$ and 10 minutes after the excitation had stopped. In this way, one can distinguish between the 'fast' and the 'slow' components in the decay profiles. Clearly all powders, including $\mathrm{Ca}_{2} \mathrm{Si}_{5} \mathrm{~N}_{8}$ :Eu, possess a significant afterglow. The addition of Nd, Dy or Ho hardly alters the decay profile or the intensity of the afterglow. Adding Sm has a detrimental effect, especially shortly after the excitation. Adding $0.5 \% \mathrm{Tm}$ to $\mathrm{Ca}_{2} \mathrm{Si}_{5} \mathrm{~N}_{8}: \mathrm{Eu}[1 \%]$, only moderately increases the afterglow intensity in the beginning of the decay curve. The main effect is an enhancement of the 'slow' component (approximately an increase by a factor of 4 compared to $\mathrm{Ca}_{2} \mathrm{Si}_{5} \mathrm{~N}_{8}: \mathrm{Eu}[1 \%] 15$ minutes after the excitation).

For the studied $\mathrm{Ca}_{2} \mathrm{Si}_{5} \mathrm{~N}_{8}: \mathrm{Eu}[1 \%], \mathrm{RE}[0.5 \%]$ powders, codoping with $\mathrm{Tm}$ is clearly the best option. Then the concentration of Eu and Tm was changed, to assess their influence on the intensity of the persistent luminescence. Increasing the europium concentration (while keeping [Tm] fixed at 0.5\%), enhances the 'fast' component while the effect on the 'slow' component is very limited. For an europium concentration of $1 \%$, increasing the Tm concentration intensifies the afterglow considerably, especially the 'slow' component.

To elucidate the observed effects of the rare earth codoping on the persistence behaviour, thermoluminescence glow curves were recorded (Fig. 4). The powders were first cooled to $10 \mathrm{~K}$ and excited at $400 \mathrm{~nm}$. Then the thermoluminescence intensity was measured upon heating the powders with a constant rate of $6.6 \mathrm{~K} / \mathrm{min}$ up to $475 \mathrm{~K}$.

The TL glow curve of $\mathrm{Ca}_{2} \mathrm{Si}_{5} \mathrm{~N}_{8}: \mathrm{Eu}$ (without codopants) is characterized by three major peaks (Fig. 4). The main one is situated at about $100 \mathrm{~K}$, although its shape suggests multiple components. A second peak, extending beyond room temperature, peaks at 200 to $220 \mathrm{~K}$. Beyond $450 \mathrm{~K}$, a third glow peak emerges, although this peak could not be fully recorded due to the temperature limitation of the cryostat. The addition of codopants introduces other glow peaks, superposed on the features 
observed for $\mathrm{Ca}_{2} \mathrm{Si}_{5} \mathrm{~N}_{8}$ :Eu. Codoping with Nd, Dy and Ho yields additional peaks at approximately 175 $\mathrm{K}, 205 \mathrm{~K}$ and $215 \mathrm{~K}$ respectively. As these glow peaks are largely situated below room temperature, they do not contribute to the persistent luminescence observed at room temperature (Fig. 3). When adding thulium, a broad glow peak is introduced around $280 \mathrm{~K}$. For the sample with increased Tm concentration $\left(\mathrm{Ca}_{2} \mathrm{Si}_{5} \mathrm{~N}_{8}: \mathrm{Eu}[1 \%], \mathrm{Tm}[3.5 \%]\right)$, this broad peak intensifies (Fig. 4) and shows two maxima at $265 \mathrm{~K}$ and $340 \mathrm{~K}$. These observations are fully in line with the observed decay profiles (Fig. 2). The 'fast' component in the decay profile of $\mathrm{Ca}_{2} \mathrm{Si}_{5} \mathrm{~N}_{8}: \mathrm{Eu}(-, \mathrm{Nd}, \mathrm{Dy}, \mathrm{Ho})$ is related to the tail of the broad TL peak extending beyond room temperature (Fig. 4), which is already present for $\mathrm{Ca}_{2} \mathrm{Si}_{5} \mathrm{~N}_{8}: \mathrm{Eu}$ without codopants. The addition of Tm introduces 'slow' components in the decay profile, related to the additional TL peak above room temperature.

\section{Discussion.}

The emission spectrum of the persistent luminescence is slightly red-shifted compared to the spectrum of the steady state luminescence (Fig. 1). Li et al. suggested that the broad emission spectrum of $\mathrm{Ca}_{2} \mathrm{Si}_{5} \mathrm{~N}_{8}: \mathrm{Eu}$ is due to the two crystallographic Ca-sites which can be occupied by the europium ions, with both sites giving rise to different emission spectra [10]. This might be related to the difference between the steady state and the persistent luminescence, if the defect centers involved in the persistent luminescence have a site preferency. However, the evidence for two different emission centers in $\mathrm{Ca}_{2} \mathrm{Si}_{5} \mathrm{~N}_{8}$ :Eu was not conclusive from the data shown by Li et al. Clabau et al. also observed a red-shift of the persistence emission spectrum compared to the steady state photoluminescence in aluminosilicate compounds [11], though much more pronounced. They related the origin of this red-shift to $\mathrm{Eu}^{2+}$ ions on perturbed (alkaline earth) crystal sites with an oxygen vacancy in close proximity, thus altering the emission spectrum. For $\mathrm{Ca}_{2} \mathrm{SiS}_{4}: \mathrm{Eu}, \mathrm{Nd}$, Smet et al. derived that a strong coupling exists between the activator $\left(\mathrm{Eu}^{2+}\right)$ and the charge traps $\left(\mathrm{Nd}^{3+}\right.$ and/or other defects) [5]. Hence it is not clear yet what the exact nature is of the difference in persistence and steady-state emission in $\mathrm{Ca}_{2} \mathrm{Si}_{5} \mathrm{~N}_{8}: \mathrm{Eu}, \mathrm{RE}$.

From the TL glow curve of $\mathrm{Ca}_{2} \mathrm{Si}_{5} \mathrm{~N}_{8}$ :Eu (Fig. 4, bottom curve), it is obvious that several defect states are already present without rare-earth codoping, both shallow and deep traps. Currently it is not clear what is the nature of these traps, and whether they are related to the preparation technique and/or the presence of impurities in the precursors. A solubility limit of $7 \%$ for Eu substitution of the Ca ions was reported in $\mathrm{Ca}_{2} \mathrm{Si}_{5} \mathrm{~N}_{8}[10]$. In all powders, the Eu concentration was well below this limit. 
Elemental EDX mapping in a scanning electron microscope of $\mathrm{Ca}_{2} \mathrm{Si}_{5} \mathrm{~N}_{8}: \mathrm{Eu}[2.5 \%], \operatorname{Tm}[2 \%]$ revealed a homogeneous distribution of the Eu doping in the powder, within the detection limit of the system. The distribution of Tm was however not homogeneous, with the presence of micron-sized thulium-rich compounds (Fig. 5). Further research will aim at an improved incorporation of the rare earth ions in the $\mathrm{Ca}_{2} \mathrm{Si}_{5} \mathrm{~N}_{8}$ lattice. This will presumably improve the persistence intensity, as an increase in the Tm concentration enhances the afterglow intensity (Fig. 3).

Codoping $\mathrm{Ca}_{2} \mathrm{Si}_{5} \mathrm{~N}_{8}$ : Eu with other rare earth elements leads to additional glow peaks in the TL spectrum. The trap depth of Nd, Dy and Ho is comparable (with the trap depth slightly increasing in the order $\mathrm{Nd}<\mathrm{Dy}<\mathrm{Ho}$ ), while Tm causes much deeper traps. This is fully in line with the observations by Dorenbos [14]. When plotting the energy position of the ground state of the rare earth ions in their divalent ground state, a fixed pattern is obtained, irrespective of the host material. This model was succesfully used to explain the thermoluminescence and the persistent luminescence of several kinds of phosphors [16, 17]. Consequently, it can be expected that the $\mathrm{RE}^{2+}$ (ground state) energy levels are at least playing a role in the charge trapping process in $\mathrm{Ca}_{2} \mathrm{Si}_{5} \mathrm{~N}_{8}: \mathrm{Eu}, \mathrm{RE}$, irrespective of the involvement of charge compensation defects [15]. Using Dorenbos' formalism, the incorporation of $\mathrm{Sm}^{3+}$ would lead to a $\mathrm{Sm}^{2+}$ ground state about $0.5 \mathrm{eV}$ deeper than $\mathrm{Tm}^{2+}$ [14]. However, the addition of Sm to $\mathrm{Ca}_{2} \mathrm{Si}_{5} \mathrm{~N}_{8}: \mathrm{Eu}$ partially suppresses the persistent emission. As argued by Hölsä et al. (in the case of $\left.\mathrm{CaAl}_{2} \mathrm{O}_{4}: \mathrm{Eu}\right) \mathrm{Sm}^{3+}$ is easily reduced to $\mathrm{Sm}^{2+}$, hence the incorporation of the divalent $\mathrm{Sm}$ ion during the synthesis does not create additional (charge compensating) defects [18]. However, the detrimental effect of adding $\mathrm{Sm}$ to $\mathrm{Ca}_{2} \mathrm{Si}_{5} \mathrm{~N}_{8}$ : Eu appears less pronounced than in the case of $\mathrm{CaAl}_{2} \mathrm{O}_{4}: \mathrm{Eu}$, possibly due to a non-homogeneous incorporation.

The afterglow of $\mathrm{Ca}_{2} \mathrm{Si}_{5} \mathrm{~N}_{8}: \mathrm{Eu}, \mathrm{Tm}$ powders can be perceived by the dark-adapted eye for about $1 \mathrm{~h}$, which should obviously be lengthened for commercial applications. This might be realised by an improvement of the synthesis conditions. The main component in the decay profile of $\mathrm{Ca}_{2} \mathrm{Si}_{5} \mathrm{~N}_{8}: \mathrm{Eu}, \mathrm{Tm}$ has a decay time of approximately one hour, which makes the trap depth appropriate for long-lasting afterglow.

\section{Conclusions and perspectives.}

In this work we presented the persistent luminescence in rare-earth codoped $\mathrm{Ca}_{2} \mathrm{Si}_{5} \mathrm{~N}_{8}:$ Eu powder. The persistence emission spectrum is red-shifted by about $10 \mathrm{~nm}$ compared to the steady state lumi- 
nescence. Of all the codopants studied, only thulium considerably enhances the persistence intensity. This work showed the occurrence of persistent luminescence in europium-doped nitrides, being a large class of luminescent materials emitting in the yellow-to-red part of the visible spectrum. Hence, other appropriate combinations of hosts and co-dopants might be found for efficient persistent luminescence. An improvement of the synthesis conditions $\left(\mathrm{Ca}_{3} \mathrm{~N}_{2}: \mathrm{Si}_{3} \mathrm{~N}_{4}\right.$ ratio, dopant distribution, ,..) is expected to have a positive effect on the intensity of the persistent luminescence.

Further research will aim at studying the nature of the defects introduced by the rare-earth codopants, which could not be elucidated in this work yet. Also, it is interesting to note that the persistence luminescence can be excited in the visible part of the spectrum, which is an advantage over other persistent materials with yellow-to-red emission colour.

\section{Acknowledgments.}

One of the authors (PFS) is a post-doctoral research fellow of FWO-Vlaanderen. This research was carried out under the Interuniversity attraction poles programme IAP/VI-17 (INANOMAT) financed by the Belgian State, Federal science policy office. 


\section{References}

[1] D. Poelman, N. Avci and P.F. Smet, Opt. Express 17 (2009) 358-364

[2] T. Matsuzawa, Y. Aoki, N. Takeuchi and Y. Murayama, J. Electrochem. Soc. 143 (1996) 2670-2673

[3] J. Hölsä, H. Jungner, M. Lastusaari and J. Niittykoski, J. Alloy. Compd. 323 (2001) 326-330

[4] Y.H. Lin, Z.L. Tang, Z.T. Zhang, X.X. Wang and J.Y. Zhang, Journal of Materials Science Letters 20 (2001) 1505-1506

[5] P.F. Smet, N. Avci and D. Poelman, J. Electrochem. Soc. 156 (2009) H243-H248

[6] X. Wang, Z. Zhang, Z. Tang and Y. Lin, Materials Chemistry and Physics 80 (2003) 1-5

[7] Z. Hong, P. Zhang, X. Fan and M. Wang, J. Lumin. 124 (2007) 127-132

[8] P. Dorenbos, J. Lumin. 104 (2003) 239-260

[9] R. Mueller-Mach, G. Mueller, M.R. Krames, H.A. Hoppe, F. Stadler, W. Schnick, T. Juestel and P. Schmidt, Phys. Status Solidi A-Appl. Mat. 202 (2005) 1727-1732

[10] Y.Q. Li, J.E.J. van Steen, J.W.H. van Krevel, G. Botty, A.C.A. Delsing, F.J. DiSalvo, G. de With and H.T. Hintzen, J. Alloy. Compd. 417 (2006) 273-279

[11] F. Clabau, A. Garcia, P. Bonville, D. Gonbeau, T. Le Mercier, P. Deniard and S. Jobic, Journal of Solid State Chemistry 181 (2008) 1456-1461

[12] P.F. Smet, J.E. Van Haecke and D. Poelman, J. Microsc.-Oxf. 231 (2008) 1-8

[13] C.M. Fang, H.T. Hintzen, G. de With and R.A. de Groot, J. Phys.-Condens. Matter 13 (2001) $67-76$

[14] P. Dorenbos, J. Phys.-Condens. Matter 15 (2003) 8417-8434

[15] H. Furusho, J. Hölsä, T. Laamanen, Mika Lastusaari, J. Niittykoski, Y. Okajima and A. Yamamoto, J. Lumin. 128 (2008) 881-884

[16] A.J.J. Bos, P. Dorenbos, A. Bessiere and B. Viana, Radiat. Meas 43 (2008) 222-226

[17] P. Dorenbos, J. Lumin. 122-123 (2007) 315-317 
[18] J. Hölsä, T. Aitasalo, H. Jungner, M. Lastusaari, J. Niittykoski and G. Spano, J. Alloy. Compd. $374(2004) 56-59$ 


\section{Figure Captions.}

Figure 1. (a) Steady state excitation spectrum for $\mathrm{Ca}_{2} \mathrm{Si}_{5} \mathrm{~N}_{8}: \mathrm{Eu}[1 \%]$ by monitoring the emission at $610 \mathrm{~nm}$. (b) Steady state emission spectrum for $\mathrm{Ca}_{2} \mathrm{Si}_{5} \mathrm{~N}_{8}: \mathrm{Eu}[1 \%]$ upon excitation at $400 \mathrm{~nm}$. (c) Persistent emission spectrum for $\mathrm{Ca}_{2} \mathrm{Si}_{5} \mathrm{~N}_{8}: \mathrm{Eu}[1 \%], \mathrm{Tm}[0.5 \%]$.

Figure 2. Decay profiles for the persistent luminescence of $\mathrm{Ca}_{2} \mathrm{Si}_{5} \mathrm{~N}_{8}: \mathrm{Eu}[1 \%]$ with and without codopants. The powders were excited at $400 \mathrm{~nm}$.

Figure 3. Intensity of the persistent luminescence for $\mathrm{Ca}_{2} \mathrm{Si}_{5} \mathrm{~N}_{8}, \mathrm{RE}$ measured $20 \mathrm{~s}$ and $600 \mathrm{~s}$ after the excitation at $400 \mathrm{~nm}$ was stopped.

Figure 4. Normalized thermoluminescence glow curves of $\mathrm{Ca}_{2} \mathrm{Si}_{5} \mathrm{~N}_{8}: \mathrm{Eu}[1 \%], \mathrm{RE}[0.5 \%]$ powders measured upon monitoring the emission at $620 \mathrm{~nm}$. The spectra were displaced vertically for improved visibility. The bottom glow curve belongs to $\mathrm{Ca}_{2} \mathrm{Si}_{5} \mathrm{~N}_{8}: \mathrm{Eu}[1 \%]$, the top one to $\mathrm{Ca}_{2} \mathrm{Si}_{5} \mathrm{~N}_{8}: \mathrm{Eu}[1 \%], \operatorname{Tm}[3.5 \%]$.

Figure 5. Scanning electron microscope image (left) and elemental EDX maps (right) of $\mathrm{Ca}_{2} \mathrm{Si}_{5} \mathrm{~N}_{8}$ :Eu[2.5\%],Tm[2\%] powder. Elemental maps were obtained for Ca-K, Si-K, Tm-L and Eu-L. 'CL' refers to the cathodoluminescence intensity. The arrows point towards a Tm-rich region. 


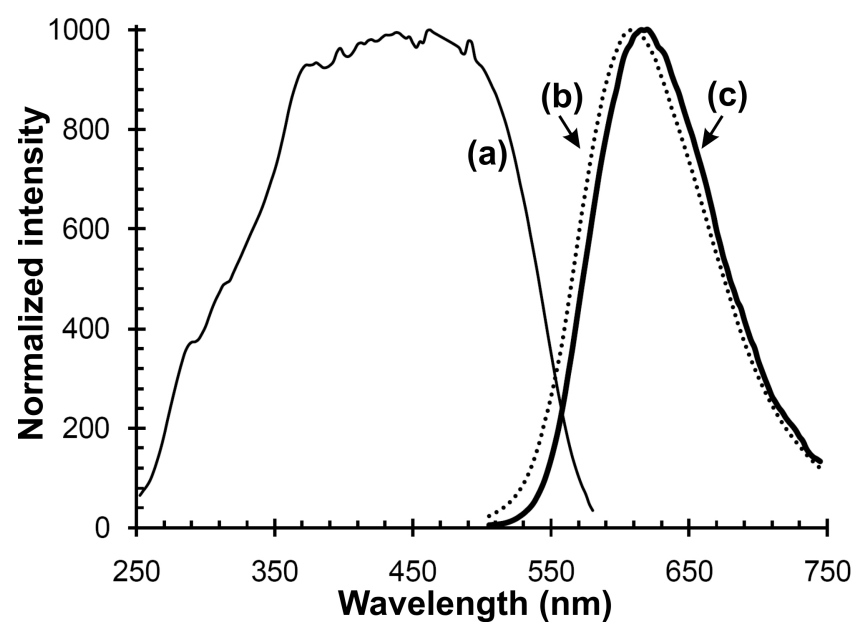

Figure 1: (a) Steady state excitation spectrum for $\mathrm{Ca}_{2} \mathrm{Si}_{5} \mathrm{~N}_{8}: \mathrm{Eu}[1 \%]$ by monitoring the emission at $610 \mathrm{~nm}$. (b) Steady state emission spectrum for $\mathrm{Ca}_{2} \mathrm{Si}_{5} \mathrm{~N}_{8}: \mathrm{Eu}[1 \%]$ upon excitation at $400 \mathrm{~nm}$. (c) Persistent emission spectrum for $\mathbf{C a}_{2} \mathbf{S i}_{5} \mathbf{N}_{8}: \mathbf{E u}[1 \%], \mathbf{T m}[0.5 \%]$. 


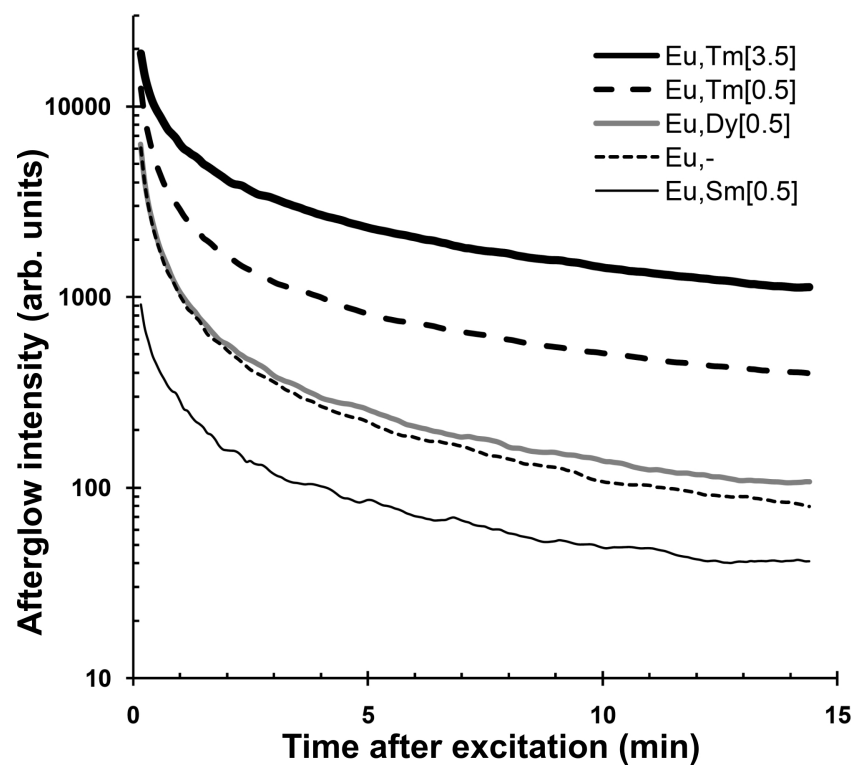

Figure 2: Decay profiles for the persistent luminescence of $\mathrm{Ca}_{2} \mathrm{Si}_{5} \mathbf{N}_{8}: \mathbf{E u}[1 \%]$ with and without codopants. The powders were excited at $400 \mathrm{~nm}$. 


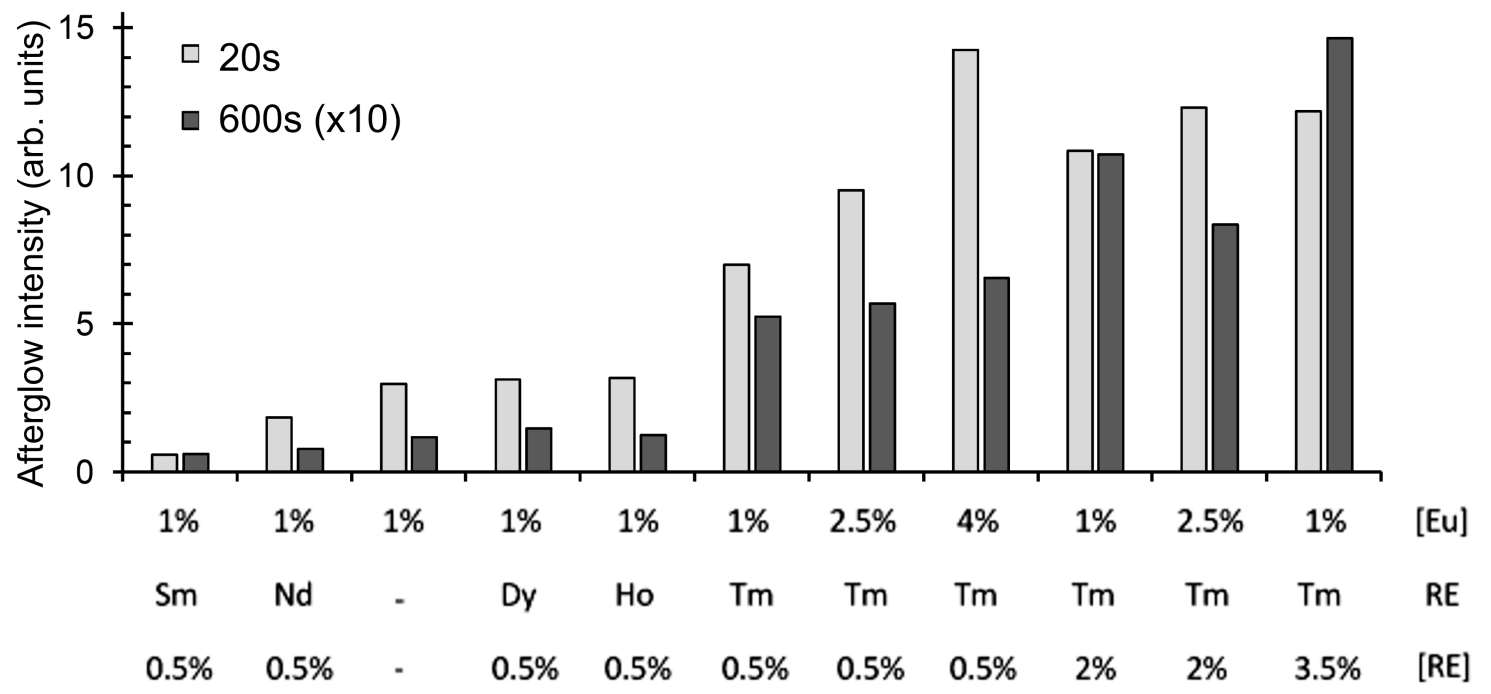

Figure 3: Intensity of the persistent luminescence for $\mathrm{Ca}_{2} \mathrm{Si}_{5} \mathrm{~N}_{8}, \mathrm{RE}$ measured $20 \mathrm{~s}$ and $600 \mathrm{~s}$ after the excitation at $400 \mathrm{~nm}$ was stopped. 


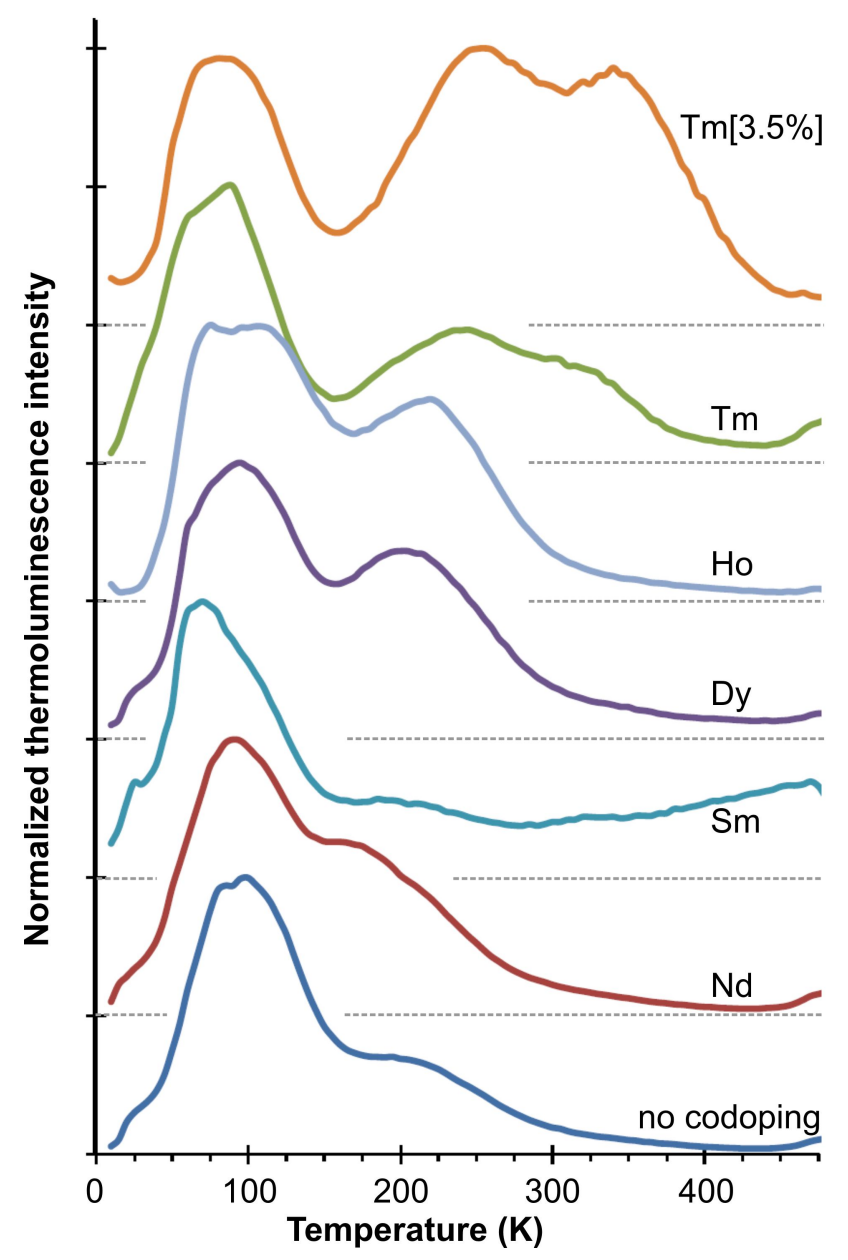

Figure 4: Normalized thermoluminescence glow curves of $\mathbf{C a}_{2} \mathbf{S i}_{5} \mathbf{N}_{8}: \mathbf{E u}[1 \%], \mathbf{R E}[0.5 \%]$ powders measured upon monitoring the emission at $620 \mathrm{~nm}$. The spectra were displaced vertically for improved visibility. The bottom glow curve belongs to $\mathrm{Ca}_{2} \mathbf{S i}_{5} \mathbf{N}_{8}: \mathrm{Eu}[1 \%]$, the top one to $\mathbf{C a}_{2} \mathbf{S i}_{5} \mathbf{N}_{8}: \mathbf{E u}[1 \%], \mathbf{T m}[3.5 \%]$. 

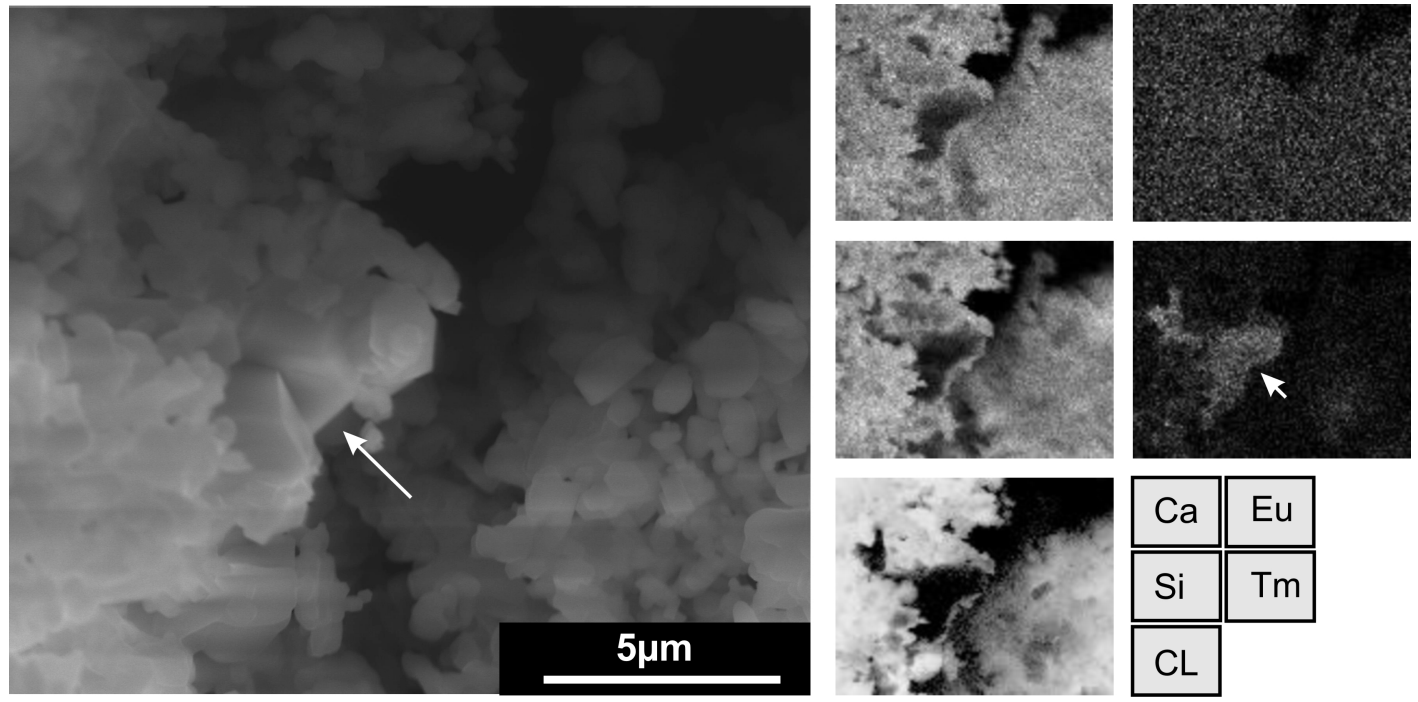

Figure 5: Scanning electron microscope image (left) and elemental EDX maps (right) of $\mathrm{Ca}_{2} \mathbf{S i}_{5} \mathbf{N}_{8}: \mathbf{E u}[2.5 \%], \mathbf{T m}[2 \%]$ powder. Elemental maps were obtained for Ca-K, Si-K, Tm-L and Eu-L. 'CL' refers to the cathodoluminescence intensity. The arrows point towards a Tm-rich region. 